\title{
Hibrit Elektrokoagülasyon/Elektrooksidasyon Prosesleri ile Denim Ürün Üretim Atıksularının Arıtımı
}

\author{
Murat SOLAK*1잉 \\ ${ }^{1}$ Düzce Üniversitesi, Mühendislik Fakültesi, Çevre Mühendisliği Bölümü, 81620, Düzce, Türkiye
}

(Alınış / Received: 27.02.2019, Kabul / Accepted: 11.10.2019, Online Yayınlanma / Published Online: 30.12.2019)

\author{
Anahtar Kelimeler \\ Elektrokoagülasyon, \\ Elektrooksidasyon, \\ Denim ürün üretim atıksuyu, \\ $\mathrm{Al}$ elektrot, \\ Titanyum elektrot, \\ Paslanmaz çelik elektrot
}

Özet: Çalışmada, denim ürün işleme atıksularının hibrit Elektrokoagülasyon (EK) ve Elektrooksidasyon (EO) Prosesleri ile arıtımı incelenmiştir. $\mathrm{pH}$, akım yoğunluğu ve elektroliz süresi gibi işletme parametrelerinin KOİ (Kimyasal Oksijen İhtiyacı) ve TÇK (Toplam Çözünmüş Katı) giderimi üzerindeki etkileri belirlenmiştir. pH değerinin 7,48, akım yoğunluğunun $120 \mathrm{~A} / \mathrm{m}^{2}$ ve elektroliz süresinin 49,5 dakika olduğu Al (Alüminyum) elektrotlarının kullanıldığı EK prosesi ile >\% 65 KOİ ve \% 51 TÇK giderimi sağlanmıştır. Aynı koşullarda, EO işleminin KOİ ve TÇK için Ti (Titanyum)/PÇ (Paslanmaz Çelik) elektrotları ile giderim verimleri sırasıyla $\%>70$ ve $\% 45$ olarak bulunmuştur. Optimum koşullarda EK/EO hibrit prosesinin renk giderim verimi \% $84(436 \mathrm{~nm}), \% 93(525 \mathrm{~nm}), \% 97(620 \mathrm{~nm})$ olarak elde edilirken, EK ve EO prosesinin enerji tüketimi sırasıyla 14,26 $\mathrm{kWsa} / \mathrm{m}^{3}$ ve $22,71 \mathrm{kWsa} / \mathrm{m}^{3}$ olarak tespit edilmiștir. Ayrıca, istatistiksel analiz sonucunda elde edilen $\mathrm{R}^{2}$ ve $\mathrm{R}^{2}$ adj değerlerinin 1 'e yakın olması, deney sonuçlarının ve istatistiksel çıkarımların uyumlu olduğunu ve işlem parametrelerinin etkilerinin belirlenmesinde BoxBehnken istatistiksel tasarımının etkili olduğunu göstermiştir.

\section{Treatment of Denim Product Manufacturing Wastewater by Hybrid Electrocoagulation/Electrooxidation Processes}

\author{
Keywords \\ Electrocoagulation \\ Electrooxidation, \\ Denim product processing wastewater, \\ Al electrode, \\ Titanium electrode, \\ Stainless steel electrode
}

\begin{abstract}
In this study, treatment of denim product processing wastewaters by hybrid electrocoagulation (EC) and electrooxidation (EOx) process were investigated. Effects of operating parameters such as $\mathrm{pH}$, current density and electrolysis time on removal of COD (Chemical Oxygen Demand) and TDS (Total Dissolved Solids) were determined. EC process with $\mathrm{Al}$ electrodes where the $\mathrm{pH}$ value was 7,48 , current density was $120 \mathrm{~A} / \mathrm{m}^{2}$, and electrolysis time was $49,5 \mathrm{~min}$ resulted in $>65 \%$ COD and $51 \%$ TDS removal. At the same conditions removal efficiencies of EOx process for COD and TDS with Ti/SS electrodes were found to be $>\% 70$ and $\% 45$, respectively. The color removal efficiency of EC / EO hybrid process at optimum conditions was obtained as $84 \%(436 \mathrm{~nm}), 93 \%(525 \mathrm{~nm}), 97 \%(620 \mathrm{~nm})$, while the energy consumption of EC and EO process was $14,26 \mathrm{kWh} / \mathrm{m}^{3}$ and 22 $\mathrm{kWh} / \mathrm{m}^{3}$ respectively. The coefficient of determination $\left(\mathrm{R}^{2}\right)$ value for removal of COD and TDS in the EC and EOx reactor, was found to be 0.99 and 0.97 , and $\mathrm{R}^{2}$ Adj value was found to be 0,96 and 0,92 , respectively. In addition, the results of the statistical analysis indicated that the $\mathrm{R}^{2}$ and $\mathrm{R}^{2}$ adj values were close to 1 indicates that the experimental results and statistical inferences were compatible and the Box-Behnken statistical design was effective in order to determine the effects of process parameters.
\end{abstract}




\section{Giriş}

Denim ürün üretim sektörü, kot pantolon (jeans), kot ceket, kot etek gibi tekstil ürünlerinin üretimini kapsamaktadır. Üretim süreçlerinde, sözkonusu tekstil ürününe istenen özellikleri kazandırmak adına boyama, kot ürünün çekmemesi, eski görünümünün kazandırılması adına çeşitli kompleks kimyasallar kullanılmaktadır. Ayrıca, üretim süreçlerinde oldukça fazla miktarda su tüketimi gerçekleşmektedir. Yüksek su tüketimi ile birlikte yüksek kirletici içeriğine sahip atıksular oluşmaktadır.

İlk yatırım, işletme ve bakım süreçlerindeki kolaylıkları bakımından tekstil atıksularının arıtımında genellikle koagülasyon-flokülasyon prosesleri kullanılmaktadır. Bu tür konvansiyonel arıtma tekniklerine alternatif teknolojiler üzerine çalışmalar yürütülmektedir. Gelişen çevre teknolojileri alanında elektrokimyasal prosesler de yerini almaktadır. Elektrokimyasal proseslerden biri olan EK prosesi $\mathrm{Al}$ ve $\mathrm{Fe}$ gibi çözünür elektrotların kullanılarak redoks reaksiyonlarına bağlı olarak anot materyalinde gerçekleşen çözünme ve oluşan hidroksit iyonları ile kirleticilerin koagüle edilerek giderildiği proseslerdir. EK prosesinin 3 aşamada gerçekleştiği kabul edilmektedir. i) Kullanılan elektrodun, elektrolitik oksidasyonu ile koagülantların olușturulması, ii) Kirleticilerin, askıdaki partiküllerin destabilizasyonu ve emülsiyonların kırılması, iii) Flokları oluşturmak için destabilize fazların birleşmesi ya da toplanması [1-3].

$\mathrm{Al}$ elektrot kullanılması durumunda anot ve katotta elektrotlarda gerçekleşen reaksiyonlar Eşitlik 1-3'te görülmektedir [4].

Anodik Reaksiyonlar

$$
A l \rightarrow A l^{3+}+3 e^{-}
$$

Katodik Reaksiyonlar

$$
3 \mathrm{H}_{2} \mathrm{O}+3 e^{-} \rightarrow 3 / 2 \mathrm{H}_{2}+3 \mathrm{OH}^{-}
$$

Çözeltide

$$
\mathrm{Al}^{3+}+3 \mathrm{H}_{2} \mathrm{O} \rightarrow \mathrm{Al}(\mathrm{OH})_{3}+3 \mathrm{H}^{+}
$$

Elektrokimyasal proseslerden biri olan elektrooksidasyon prosesi ise kullanılan titanyum, platin, rubidyum, grafit gibi çözünmez elektrotlar ile atıksu ortamındaki kirleticilerin hidroksi radikallerinin oluşumu ile okside edildiği prosestir. Elektrooksidasyon prosesinde kirletici giderimi iki temel mekanizma ile gerçekleşmektedir. Birincisi, kullanılan anot elektrotta gerçekleşen doğrudan oksidasyon ve atıksu ortamında oksitleyiciler ile gerçekleşen dolaylı oksidasyondur. Elektrooksidasyon prosesi sirasinda her iki mekanizma da çalışmaktadır $[5,6]$. Doğrudan oksidasyon prosesinde kirleticiler anot yüzeyine adsorbe olurlar ve anodik elektron transferi reaksiyonu ile giderilirler. Dolaylı oksidasyon prosesinde hipoklorit/klor, ozon ve hidrojen peroksit gibi kuvvetli oksitleyiciler elektrokimyasal olarak üretilir. Kirleticiler ise üretilen bu oksitleyici maddeler ile okside edilerek giderilir [7, 8].

EO prosesinde atıksu ortamında anodik ve katodik olarak gerçekleşen reaksiyonlar Eşitlik 4-10'da görülmektedir. EO prosesi atıksu ortamında bulunan organik kirleticileri tamamen karbondioksite mineralize eder ve bu organik maddeler anodik elektron transfer reaksiyonu ve aritma sirasinda üretilen hidroksiradikaller, hidrojen peroksit ve hipoklorit, klor gibi kirletici giderim verimini artıran kuvvetli oksidantların üretimi ile okside edilir [8].

$\underline{\text { Anodik Reaksiyonlar }}$

$$
\begin{gathered}
\mathrm{H}_{2} \mathrm{O} \rightarrow \mathrm{OH}^{-}+\mathrm{H}^{+}+e^{-} \\
\mathrm{Cl}^{-} \rightarrow \mathrm{Cl}+e^{-} \\
\mathrm{Cl} \cdot \rightarrow \mathrm{Cl}_{2} \\
2 \mathrm{OH}^{\cdot} \rightarrow \mathrm{H}_{2} \mathrm{O}_{2}
\end{gathered}
$$

$\underline{\text { Katodik Reaksiyonlar }}$

$$
\begin{gathered}
\mathrm{SO}_{4}^{2-}+\mathrm{H}_{2} \mathrm{O}+2 e^{-} \rightarrow \mathrm{SO}_{3}^{2-}+2 \mathrm{OH}^{-} \\
\mathrm{HCO}_{3}^{-}+\mathrm{OH}^{-} \rightarrow \mathrm{CO}_{3}^{2-}+\mathrm{H}_{2} \mathrm{O} \\
\mathrm{Ca}^{2+}+\mathrm{CO}_{3}^{2-} \rightarrow \mathrm{CaCO}_{3}
\end{gathered}
$$

$\mathrm{Bu}$ çalışmada da elektrokimyasal proseslerden EK ve EO prosesleri ile denim ürün üretimi atıksularının arıtımı gerçekleştirilmiştir. Literatürde elektrokimyasal prosesler ile tekstil atıksularının arıtımı üzerine oldukça fazla çalışma bulunmaktadır [9-15]. Bu çalışmada hibrit bir proses olarak EK/EO proseslerinin denim ürün üretim atıksularından KOİ ve TÇK gideriminin etkinliği araştırılmıştır. Atıksu ilk aşamada $\mathrm{Al}$ elektrodunun kullanıldığı EK prosesine, ikinci aşamada da EK prosesinden çıkan atıksuya Ti (Titanyum)/PÇ (Paslanmaz Çelik) elektrotların kullanıldığı elektrooksidasyon prosesi uygulanmıştır. Proses işletme şartlarını belirleyen $\mathrm{pH}$, akım yoğunluğu ve elektroliz süresi gibi parametreler optimize edilerek, elde edilen sonuçlar istatistiksel olarak değerlendirilmiştir.

\section{Materyal ve Metot}

Ham atıksuyun karakterizasyonu Tablo 1'de görülmektedir. Ham atıksu denim ürün üretimi yapan bir tekstil firmasının atıksu arıtma tesisi girişinden alınmıştır. 
Tablo 1. Ham atıksu karakterizasyonu

\begin{tabular}{|l|l|}
\hline Parametre & Değer/Konsantrasyon \\
\hline $\mathrm{pH}$ & $8,37 \pm 0,2$ \\
\hline KOİ & $380 \pm 25 \mathrm{mg} / \mathrm{L}$ \\
\hline TÇK & $3,17 \pm 0,2 \mathrm{~g} / \mathrm{L}$ \\
\hline İletkenlik & $6,22 \pm 0,3 \mathrm{mS} / \mathrm{cm}$ \\
\hline & $436 \mathrm{~nm}-1,04 \mathrm{~m}^{-1}$ \\
Renk & $525 \mathrm{~nm}-1,27 \mathrm{~m}^{-1}$ \\
& $620 \mathrm{~nm}-2,45 \mathrm{~m}^{-1}$ \\
\hline
\end{tabular}

\subsection{Elektrokoagülasyon ve Elektrooksidasyon Prosesi Model Reaktörleri}

EK/EO prosesinin deney düzeneğinin gösterimi Şekil 1'de görülmektedir. Model reaktörün boyutları HxBXL 85x80x80 mm, hacmi $500 \mathrm{~mL}$ olarak tasarlanmıştır. Model reaktörde kullanılan $\mathrm{Al}$, Ti ve PÇ elektrotlarının boyutları sırasıyla $40 * 80 * 1 \mathrm{~mm}$, $40 * 80 * 0,1 \mathrm{~mm}$ ve $40 * 80 * 2 \mathrm{~mm}$ 'dir.

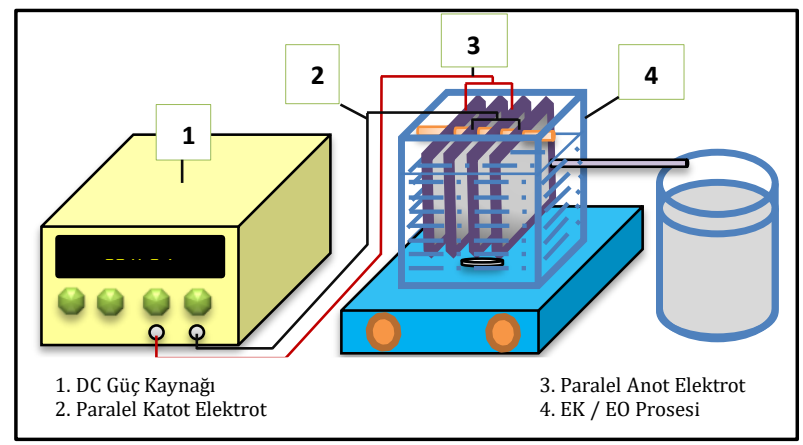

Şekil 1. EK-EOx Deney Düzeneği

\subsection{Deneysel Çalışmalar}

Kesikli şartlarda işletilen reaktöre $350 \mathrm{~mL}$ atıksu numunesi eklenerek deneysel çalışmalara bașlanmıștır. Çalıșmada EK ve EO prosesini etkileyen $\mathrm{pH}$, akım yoğunluğu ve elektroliz süresi parametrelerinin KOİ ve TÇK giderim verimine etkileri incelenmiştir. Elektrotlar, tasarlanan elektrot bağlantı sistemine yerleştirildikten sonra elektroliz işlemine başlanmıştır. Reaktör içerisinde çökelme olmaması ve giderim veriminin yükseltilmesi amacı ile çözelti içerisindeki anyon ve katyon temasını artırmak için 200 devir/dakika karıştırma hızında sürekli olarak karıștırılmıștır. EK prosesi sonrası alınan çıkış suyu, 0,45 $\mu \mathrm{m}$ gözenek çapına sahip filtreden süzüldükten sonra parametre analizleri gerçekleştirilmiştir. Daha sonra aynı reaktöre Ti/PÇ elektrotlar daldırılarak EOx prosesi uygulanmıştır. EOx prosesinden alınan çıkış suyu, 0,45 $\mu$ m gözenek çapına sahip filtreden süzüldükten sonra parametre analizleri gerçekleştirilmiştir.

\subsection{Metot}

Deneysel çalışmalarda, giriş ve çıkış suyu örneklerinde KOİ konsantrasyonlarının belirlenmesi için Standart Metot (5220 D) metot kullanılmıştır. pH ve iletkenlik, elektrometrik metoda (SM 4500-H+) göre Hanna model cihazı kullanılarak belirlenmiştir
[16]. Akım ve voltaj kontrolü Gwinstek GPS 3303 DC Power Supply (0-30V, 0-3A) model güç kaynağı ile sağlanmıştır. Karıștırma işleminde SCIlogex MSH 280-Pro model karıştırıcı kullanılmıştır. pH ölçümleri Hanna HI 2211 model pH metre ile elektrometrik, iletkenlik ve TÇK ölçümleri Hach İletkenlik-TÇK metre ile elektrometrik yöntem ile gerçekleştirilmiştir. pH ayarlamaları için $\mathrm{H}_{2} \mathrm{SO}_{4}$ ve $\mathrm{NaOH}$ çözeltileri kullanılmıştır. İletkenlik ayarlaması $\mathrm{NaCl}$ ile yapılmıştır.

\section{4. İstatistiksel Analiz}

Deneysel çalışmaların sonuçlarının değerlendirilmesi amaciyla, Box-Behnken istatistiksel modeli kullanılmıştır. Box-Behnken, dizaynı yanıt yüzey dizaynlarından biri olup, ikinci derecedir.

Atıksuyun pH değeri, akım yoğunluğu ve elektroliz süresi bağımsız değişkenler olarak ele alınmıştır. Box-Behnken istatistiksel analizi, Design Expert (trial) programı kullanılarak; ANOVA tablosu çıkarılarak, P, R², F değerleri elde edilmiştir.

Dizayn tablosuna göre yapılan deneyler sonucunda bulunan KOİ ve TÇK giderim verileri kullanılarak aşağıda verilen eșitlikte $b_{1}, b_{2}, b_{3} \ldots$ katsaylları belirlenmiştir (Eşitlik 11). Bu katsayılar kullanılarak KOİ ve TÇK giderim değerini maksimum seviyeye getirecek bağımsız parametrelerin alabileceği optimum değerler tespit edilmiştir.

$$
\begin{gathered}
Y=b_{0}+b_{1} X_{1}+b_{2} X_{2}+b_{12} X_{1} X_{2}+b_{13} X_{1} X_{3}+ \\
b_{23} X_{2} X_{3}+b_{11} X_{1}^{2}+b_{22} X_{22}^{2}+b_{33} X_{3}^{2}
\end{gathered}
$$

pH, akım yoğunluğu ve elektroliz süresi olmak üzere 3 adet bağımsız değișken için ön çalıșmalarda elde edilen aralıklar Tablo 2'de görülmektedir. Proseste uygulanan işletme şartlarına göre değişkenlere yanıt değişken olarak, işlem sonrası numunede KOİ ve TÇK giderim verimleri (\%) belirlenmiştir.

Tablo 2. Optimizasyon çalışması için proses faktörleri ve seviyeleri

\begin{tabular}{|l|c|c|c|c|}
\cline { 3 - 5 } \multicolumn{2}{c|}{} & \multicolumn{3}{c|}{ Seviyeler } \\
\hline Faktörler & Birim & $\mathbf{- 1}$ & $\mathbf{0}$ & $\mathbf{+ 1}$ \\
\hline pH & & 4 & 7,5 & 9 \\
\hline Akım Yoğunluğu & $\mathrm{A} / \mathrm{m}^{2}$ & 30 & 75 & 120 \\
\hline Elektroliz Süresi & $\mathrm{dk}$. & 5 & 27,5 & 50 \\
\hline
\end{tabular}

\section{Bulgular}

\subsection{EK/EOx Prosesi Analiz Sonuçları ve İstatistiksel Analizi}

EK ve EOx prosesi ile yapılan deneysel çalıșmalar sonucunda elde edilen sonuçlar Tablo 3'te görülmektedir. Katot elektrottaki suyun indirgenme reaksiyonu sonucunda oluşan hidroksitler atıksu $\mathrm{pH}$ değerini artırmıştır. 
EK prosesinde belirlenen 30,75 ve $120 \mathrm{~A} / \mathrm{m}^{2}$ akım yoğunluğu için atıksuya verilen akım değerlerinde (0,36 A, 0,9A 1,44 A), Voltaj 2,75-25 V aralığında değişim gösterirken, EO prosesinde aynı akım yoğunluğu parametreleri için 13,8-32 V aralığında değişim göstermiştir.

EK prosesinde elektrik tüketimi $0,24-53,6 \mathrm{kWsa} / \mathrm{m}^{3}$ aralığında değişim gösterirken, EO prosesinde ise 5,38-68,6 kWsa/m³ aralığında değişim göstermiştir. EO prosesinin enerji tüketimi, EK prosesinden fazladir.

Çalışmada başlangıç iletkenlik değerinin etkisini önlemek amacıyla, tüm deneysel çalışmalarda iletkenlik 7,5 mS/cm olarak ayarlanmıștır. EK ve EO proseslerinde iletkenlik tüm deneysel çalışmalarda azalmıştır. EK prosesinde oluşan hidroksitler bağlanan iyonlardan dolayı ve EO prosesinde gerçekleşen reaksiyonlar ile iletkenlik düşmüştür.

EK prosesinin optimizasyonu için pH, akım yoğunluğu ve elektroliz süresi gibi işletme parametrelerinin etkisi araştırılmıştır. Optimizasyon sonucu ANOVA analizi Tablo 4'te verilmiştir. İstatistiksel analiz sonucunda quadratik modele uyum sağladığı belirlenmiştir. Kuadratik model, basit doğrusal regresyonun bir uzantısıdır. Quadratik model için elde edilen verilere göre etkin parametreler, $\quad \mathrm{p}<0.05$ değerlerine göre değerlendirmiştir. Buna göre, kimyasal sprey atıksuyundan EK/EO hibrit prosesi ile KOİ ve TÇK giderim veriminde $\mathrm{pH}$, akım yoğunluğu ve elektroliz süresinin oldukça önemli parametreler olduğu belirlenmiştir.

Tablo 3. Deneysel Sonuçlar

\begin{tabular}{|c|c|c|c|c|c|c|c|c|c|c|c|c|c|c|c|}
\hline \multirow[b]{2}{*}{ No } & \multirow[b]{2}{*}{ pH } & \multirow[b]{2}{*}{$\mathrm{A} / \mathrm{m}^{2}$} & \multirow[b]{2}{*}{ dk. } & \multicolumn{2}{|c|}{ Volt } & \multicolumn{2}{|c|}{ pH } & \multicolumn{2}{|c|}{$\begin{array}{l}\text { İletkenlik } \\
\text { (mS/cm) }\end{array}$} & \multicolumn{2}{|c|}{$\begin{array}{c}\text { TÇK } \\
(\mathrm{mg} / \mathrm{L})\end{array}$} & \multicolumn{2}{|c|}{$\begin{array}{c}\text { KOI } \\
(\mathrm{mg} / \mathrm{L})\end{array}$} & \multicolumn{2}{|c|}{$\begin{array}{c}\text { Enerji } \\
\text { Tüketimi } \\
\left(\mathbf{k W s a} / \mathbf{m}^{3}\right)\end{array}$} \\
\hline & & & & EK & EO & \begin{tabular}{|c|} 
EK \\
Çıkıș
\end{tabular} & $\begin{array}{c}\text { EO } \\
\text { Çııkış }\end{array}$ & $\begin{array}{c}\text { EK } \\
\text { Çıוkıș }\end{array}$ & \begin{tabular}{|c|} 
EO \\
Çı1kış
\end{tabular} & $\begin{array}{c}\text { EK } \\
\text { Çıııș }\end{array}$ & $\begin{array}{c}\text { E0 } \\
\text { Çıkıș }\end{array}$ & $\begin{array}{c}\text { EK } \\
\text { Çıııș }\end{array}$ & $\begin{array}{c}\text { EO } \\
\text { Çıııș }\end{array}$ & EK & EO \\
\hline 1 & 4 & 30 & 27,5 & 3,2 & 13,8 & 5,91 & 5,960 & 6,03 & 5,67 & 2,96 & 2,83 & 280,00 & 263,00 & 1,51 & 6,51 \\
\hline 2 & 4 & 120 & 27,5 & 12,6 & 20,4 & 7,07 & 7,780 & 2,46 & 2,22 & 2,2 & 2,15 & 223,00 & 192,00 & 23,8 & 38,5 \\
\hline 3 & 4 & 75 & 5 & 5,5 & 25,1 & 5,57 & 7,12 & 5,92 & 5,75 & 2,95 & 2,86 & 272,00 & 250,00 & 1,18 & 5,38 \\
\hline 4 & 4 & 75 & 50 & 6,1 & 14,9 & 7,47 & 6,65 & 5,07 & 4,22 & 2,52 & 2,1 & 222,00 & 202,00 & 13,1 & 31,9 \\
\hline 5 & 6,5 & 30 & 5 & 2,75 & 17 & 7,26 & 7,01 & 6,35 & 6,13 & 2,8 & 3,06 & 279,00 & 270,00 & 0,24 & 1,46 \\
\hline 6 & 6,5 & 120 & 5 & 7,2 & 26 & 6,85 & 6,76 & 6,3 & 6,22 & 3,15 & 3,1 & 264,00 & 220,00 & 2,4 & 8,91 \\
\hline 7 & 6,5 & 30 & 50 & 4,2 & 14 & 8,13 & 6,95 & 6,04 & 5,48 & 3,01 & 2,74 & 261,00 & 223,00 & 3,6 & 12 \\
\hline 8 & 6,5 & 120 & 50 & 9,8 & 17 & 7,50 & 3,78 & 4,46 & 3,8 & 2,23 & 1,9 & 132,00 & 105,00 & 33,6 & 58,3 \\
\hline 9 & 6,5 & 75 & 27,5 & 17 & 17,5 & 7,41 & 7,77 & 5,15 & 4,97 & 2,57 & 2,38 & 212,00 & 165,00 & 20 & 20,6 \\
\hline 10 & 6,5 & 75 & 27,5 & 16,9 & 17,2 & 7,32 & 7,54 & 5,1 & 4,87 & 2,46 & 2,4 & 210,00 & 168,00 & 19,9 & 20,3 \\
\hline 11 & 6,5 & 75 & 27,5 & 16,8 & 17 & 7,38 & 7,65 & 5,12 & 4,84 & 2,52 & 2,35 & 216,00 & 163,00 & 19,8 & 20 \\
\hline 12 & 6,5 & 75 & 27,5 & 17,1 & 17,4 & 7,40 & 7,62 & 5,1 & 4,85 & 2,49 & 2,37 & 215,00 & 158,00 & 20,2 & 20,5 \\
\hline 13 & 6,5 & 75 & 27,5 & 17 & 17 & 7,00 & 7,9 & 5,13 & 4,84 & 2,56 & 2,36 & 215,00 & 162,00 & 20 & 20 \\
\hline 14 & 9 & 30 & 27,5 & 9,9 & 15 & 8,92 & 9,15 & 5,92 & 5,24 & 2,96 & 2,62 & 246,00 & 210,00 & 4,67 & 7,07 \\
\hline 15 & 9 & 120 & 27,5 & 17 & 18 & 9,09 & 7,24 & 4,42 & 3,2 & 2,2 & 2,6 & 180,00 & 140,00 & 32,1 & 33,9 \\
\hline 16 & 9 & 75 & 5 & 18,5 & 24 & 8,89 & 8,21 & 5,55 & 4,52 & 2,77 & 2,25 & 260,00 & 220,00 & 3,96 & 5,14 \\
\hline 17 & 9 & 75 & 50 & 25 & 32 & 8,60 & 8,24 & 5,32 & 4,32 & 2,17 & 2,01 & 196,00 & 182,00 & 53,6 & 68,6 \\
\hline
\end{tabular}

Tablo 4. ANOVA Analizi

\begin{tabular}{|c|c|c|c|c|c|c|c|c|c|c|}
\hline & \multicolumn{5}{|c|}{ EK Prosesi } & \multicolumn{5}{|c|}{ EOx Prosesi } \\
\hline Kaynak & $\begin{array}{c}\text { Kareler } \\
\text { Ortalaması }\end{array}$ & S.D. & $\begin{array}{c}\text { Ortalama } \\
\text { Kareler } \\
\end{array}$ & $\begin{array}{c}\mathbf{F} \\
\text { Değeri }\end{array}$ & $\begin{array}{c}\mathbf{P} \\
\text { Değeri }\end{array}$ & $\begin{array}{c}\text { Kareler } \\
\text { Ortalaması } \\
\end{array}$ & S.D. & $\begin{array}{c}\text { Ortalama } \\
\text { Kareler }\end{array}$ & $\begin{array}{c}\mathbf{F} \\
\text { Değeri }\end{array}$ & $\begin{array}{c}\mathbf{P} \\
\text { Değeri }\end{array}$ \\
\hline Model & 0,10 & 9 & 0,011 & 56,44 & $<0.0001$ & 0,21 & 9 & 0,024 & 19,18 & 0,0004 \\
\hline $\mathrm{pH}$ & $7,406 \mathrm{E}-003$ & 1 & $7,406 \mathrm{E}-003$ & 36,85 & 0,0005 & 0,021 & 1 & 0,021 & 16,87 & 0,0045 \\
\hline A.Y. & 0,037 & 1 & 0,037 & 185,85 & $<0.0001$ & 0,083 & 1 & 0,083 & 67,05 & $<0.0001$ \\
\hline E.S. & 0,037 & 1 & 0,037 & 184,75 & $<0.0001$ & 0,053 & 1 & 0,053 & 43,19 & 0,0003 \\
\hline $\mathrm{AB}$ & $8,686 \mathrm{E}-007$ & 1 & $8,686 \mathrm{E}-007$ & $\begin{array}{c}4,322 \mathrm{E}- \\
003 \\
\end{array}$ & 0,9494 & 1,731E-006 & 1 & 1,731E-006 & $\begin{array}{c}1,404 \mathrm{E} \\
-003 \\
\end{array}$ & 0,9712 \\
\hline $\mathrm{AC}$ & $1,232 \mathrm{E}-004$ & 1 & $1,232 \mathrm{E}-004$ & 0,61 & 0,4594 & $1,731 \mathrm{E}-004$ & 1 & $1,731 \mathrm{E}-004$ & 0,14 & 0,7189 \\
\hline $\mathrm{BC}$ & 0,011 & 1 & 0,011 & 55,53 & 0,0001 & $8,006 \mathrm{E}-003$ & 1 & $8,006 \mathrm{E}-003$ & 6,49 & 0,0382 \\
\hline $\mathrm{A}^{2}$ & 1,937E-003 & 1 & $1,937 \mathrm{E}-003$ & 9,64 & 0,0172 & 0,016 & 1 & 0,016 & 13,09 & 0,0085 \\
\hline $\mathrm{B}^{2}$ & 1,947E-003 & 1 & $1,947 \mathrm{E}-003$ & 9,69 & 0,0170 & 6,152E-003 & 1 & 6,152E-003 & 4,99 & 0,0606 \\
\hline $\mathrm{C}^{2}$ & $4,135 \mathrm{E}-003$ & 1 & $4,135 \mathrm{E}-003$ & 20,57 & 0,0027 & 0,021 & 1 & 0,021 & 16,96 & 0,0045 \\
\hline Artık & $1,407 \mathrm{E}-003$ & 7 & $2,010 \mathrm{E}-004$ & & & $8,629 \mathrm{E}-003$ & 7 & $1,233 \mathrm{E}-003$ & & \\
\hline $\begin{array}{l}\text { Uyum } \\
\text { Eksikliği }\end{array}$ & 1,308E-003 & 3 & $4,359 \mathrm{E}-004$ & 17,56 & 0,0091 & $8,250 \mathrm{E}-003$ & 3 & $2,750 \mathrm{E}-003$ & 28,98 & 0,0036 \\
\hline Hata & $9,92 \mathrm{n} 7 \mathrm{E}-005$ & 4 & $2,482 \mathrm{E}-005$ & & & $3,795 \mathrm{E}-004$ & 4 & $9,488 \mathrm{E}-005$ & & \\
\hline Toplam & 0,10 & 16 & & & & 0,22 & 16 & & & \\
\hline & $\mathbf{R}^{2}$ & 0,99 & & & & $\mathbf{R}^{2}$ & 0,96 & & & \\
\hline & Adj R ${ }^{2}$ & 0,97 & & & & Adj $R^{2}$ & 0,92 & & & \\
\hline
\end{tabular}

S.D.: Serbestlik Derecesi 
ANOVA analizi sonrası KOİ giderim verimi için EK ve EO prosesleri için proses parametrelerinin kendileri arasındaki ve birbiriyle olan ilișkilerini belirleyen eşitlikler aşağıdaki gibi elde edilmiştir (Eşitlik 12-13).

$$
\begin{array}{r}
\text { KOİ Giderim Verimi (\%)-EK } \\
=0,66+0,03^{*} \text { pH+0,068* A.Y. }+0,068^{*} \text { E.S. }+ \\
\text { 4.660E-004* }{ }^{*} H^{*} \text { A.Y.+5.549E-003*pH*E.S. } \\
+0.053^{*} \text { A.Y. }{ }^{*} \text { E.S. }-0.021^{*} \mathrm{pH}^{2}-0.022^{*} \text { A.Y. }{ }^{2}-
\end{array}
$$

$$
\begin{aligned}
& \text { KOİ Giderim Verimi (\%)-EO } \\
& =+0.57+0,051^{*} \text { pH+0,1* A.Y. }+0,082^{*} \text { E.S.- } \\
& \text { 6,579E-004*pH*A.Y.-6,579E-003*pH*E.S. } \\
& +0.045^{*} \text { A.Y. }{ }^{*} \text { E.S. - 0.062* } \text { pH }^{2}-0.062^{*} \text { A.Y. }
\end{aligned}
$$

$$
0.038 \text { E.S. }^{2}
$$

\section{1. pH ve Akım Yoğunluğu parametrelerinin Koİ ve TÇK Giderim Verimini Etkisi}

pH ve akım yoğunluğu parametreleri EK prosesi ile kirletici gideriminde önemli rol oynamaktadır [9]. Atıksu içerisinde düşük $\mathrm{pH}$ değerlerinde $\mathrm{Al}^{3+}$ ve $\mathrm{Al}(\mathrm{OH})_{2}{ }^{+}$gibi katyonik monomerik $\mathrm{Al}$ türleri mevcuttur. pH değeri 4-9 aralığında $\mathrm{Al}(\mathrm{OH})_{2}$ gibi monomerik bileşikler, $\mathrm{Al}_{6}(\mathrm{OH})_{15^{3+}}$ gibi polimerik bileşikler kompleks polimerizasyon ve/veya presipitasyon mekanizması ile çözünmez amorf $\mathrm{Al}(\mathrm{OH})_{3(\mathrm{~s})}$ floğuna dönüşür. pH değeri 8'den büyük

olması durumunda monomerik $\quad \mathrm{Al}(\mathrm{OH})_{4}$ konsantrasyonu artar, çözünmez amorf $\mathrm{Al}(\mathrm{OH})_{3(\mathrm{~s})}$ floğunun önemini azaltır [17].

pH değerinin nötral aralıkta olduğu, akım yoğunluğunun 100-120 A/m² olduğu şartlarda KOI giderim verimi en yüksek seviyelere ulașmıştır (Şekil 2a). Akım yoğunluğu atıksu ortamında salınan elektrot materyalini de artırarak süpürme etkisiyle kirleticilerin daha kolay gitmesini sağlamaktadır. En yüksek TÇK giderim verimi akım yoğunluğunun $>80$ $\mathrm{A} / \mathrm{m}^{2}$ ve $\mathrm{pH}$ değerinin asidik olduğu şartlarda elde edilmiştir. TÇK giderim verimi açısından akım yoğunluğu oldukça geniş aralıklarda etkin giderim sağlamıştır (Şekil 2b).

\section{2. pH ve Elektroliz Süresi parametrelerinin KOİ ve TÇK Giderim Verimine Etkisi}

pH ve elektroliz süresi parametrelerinin KOİ giderim verimine etkisine bakıldığında, elektroliz süresinin 25 dk.'nın üzerine ve geniş pH aralığında yüksek KOİ giderim verimleri elde edilmiştir (Şekil 3a).

TÇK giderim verimi açısından bakıldıgınaa ıse, elektroliz süresinin $30 \mathrm{dk}$.'nın üzerinde olduğu ve $\mathrm{pH}$ değerinin asidik șartlarda olduğu durumlarda elde edilmiştir. (Şekil 3b).

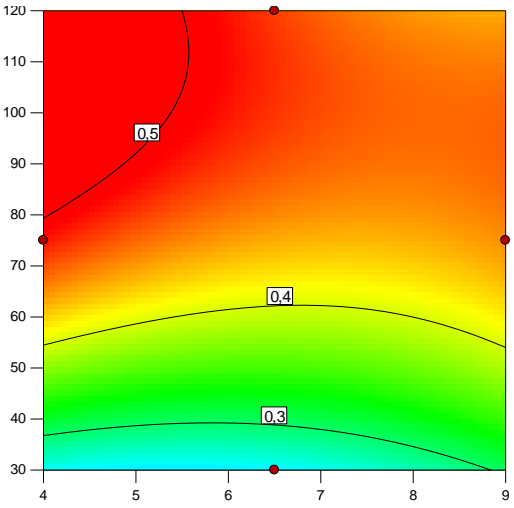

$\mathrm{pH}$

a)

$\mathrm{pH}$

Şekil 2. pH ve Akım yoğunluğu parametrelerinin a) KOİ , b) TÇK Giderimi Verimine etkisi

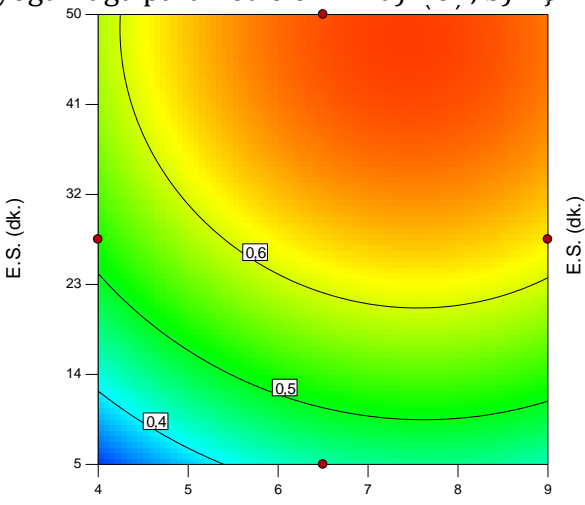

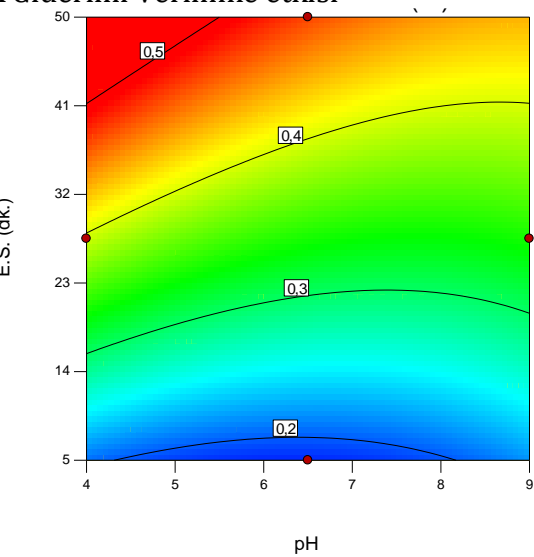

b)

Şekil 3. pH ve Elektroliz Süresi parametrelerinin a) KOİ, b) TÇK Giderimi Verimine etkisi J: Akım Yoğunluğu (A/m²), E.S. :Elektroliz Süresi 


\subsection{Akım Yoğunluğu ve Elektroliz Süresi parametrelerinin Koİ ve TÇK Giderim Verimine Etkisi}

Akım yoğunluğu Al iyonu çözünme hızını artırdığından EK prosesinde önemli bir parametredir [18]. Akım yoğunluğu, sadece koagülant dozunu değil, aynı zamanda oluşan kabarcık hızı ve boyutunu da etkilemektedir. Arıtım hızı akım yoğunluğunun yüksek olduğu değerlerde artmaktadır [8].

Çalışmada da akım yoğunluğunun $>90 \mathrm{~A} / \mathrm{m}^{2}$ olduğu ve elektoliz sürenin $>25 \mathrm{dk}$. olduğu șartlarda KOİ giderim veriminin arttığı görülmektedir (Şekil 4a). Akım yoğunluğunun artması KOİ giderim verimini artırmıştır.

TÇK giderim verimi açısından en yüksek değerlere akım yoğunluğunun $70-120 \mathrm{~A} / \mathrm{m}^{2}$ ve elektroliz süresinin $35 \mathrm{dk}$ olduğu şartlarda ulaşılmıştır (Şekil $4 b)$.

\subsection{Akım Yoğunluğu ve Elektroliz Süresi parametrelerinin EK ve EO Proseslerinde Enerji Tüketimine Etkisi}

EK ve EO gibi elektrokimyasal proseslerinde akım yoğunluğu ve elektroliz süreleri enerji tüketimini etkileyen en önemli parametrelerdir. EK prosesinde elektrik tüketimi $0,24-53,6 \mathrm{kWsa} / \mathrm{m}^{3}$ aralı̆̆ında değişim gösterirken, EO prosesinde ise 5,38-68,6 $\mathrm{kWsa} / \mathrm{m}^{3}$ olarak belirlenmiștir (Șekil 5a, b). Optimum koşullarda, EK ve EO prosesinin enerji tüketimi sirasiyla $14,26 \mathrm{kWsa} / \mathrm{m}^{3}$ ve $22,71 \mathrm{kWsa} / \mathrm{m}^{3}$ olarak tespit edilmiştir. EO prosesinin elektrik tüketimi EK prosesine göre yaklaşık $\% 60$ daha fazladır.

\section{Tartışma ve Sonuç}

Çalışmada, Hibrit Elektrokoagülasyon ve Elektrooksidasyon prosesleri ile denim ürün üretim atıksularının arıtımında etkin işletme parametrelerinin KOİ ve TÇK madde giderimlerine etkileri incelenmiştir. pH değerinin 7,48, akım yoğunluğunun $120 \mathrm{~A} / \mathrm{m}^{2}$ ve elektroliz süresinin 49,5 dakika olduğu $\mathrm{Al}$ elektrotlarının kullanıldığı EK prosesi ile >\% 65 KOİ ve \% 51 TÇK giderimi sağlanmıștır. Aynı koşullarda, EO işleminin KOİ ve TÇK için Ti/SS elektrotları ile giderim verimlerinin sırasiyla $>\% 70$ ve $\% 45$ olduğu bulunmuştur. EK/EO hibrit prosesinin renk giderim verimi \% $84(436 \mathrm{~nm})$, \% $93(525 \mathrm{~nm}), \% 97(620 \mathrm{~nm})$ olarak elde edilirken, EK ve EO prosesinin enerji tüketimleri sirasıyla 14,26 $\mathrm{kWsa} / \mathrm{m}^{3}$ ve $22,71 \mathrm{kWsa} / \mathrm{m}^{3}$ olarak tespit edilmiştir.

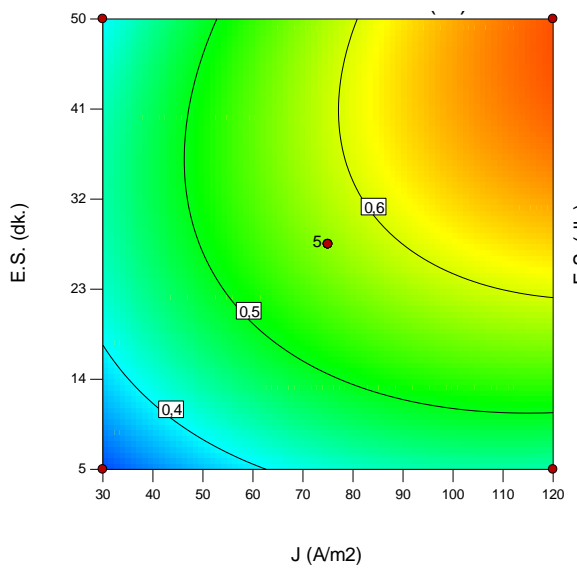

a)

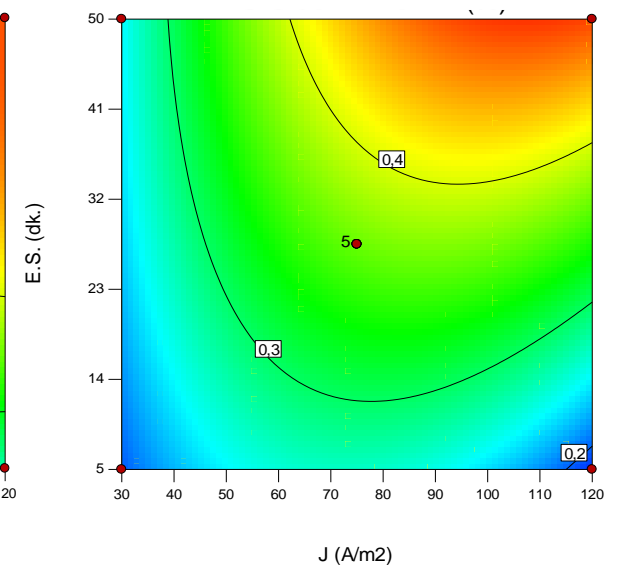

b)

Şekil 4. Akım Yoğunluğu ve Elektroliz Süresi parametrelerinin a) KOİ, b) TÇK Giderimi Verimine etkisi E.S. :Elektroliz Süresi , J: Akım Yoğunluğu $\left(\mathrm{A} / \mathrm{m}^{2}\right)$

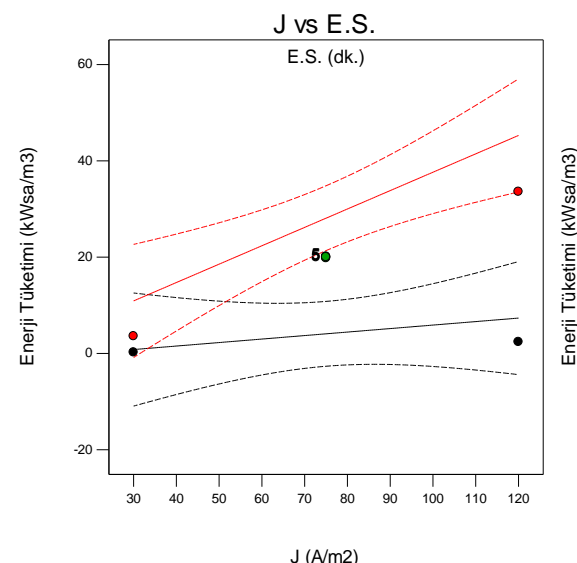

a)

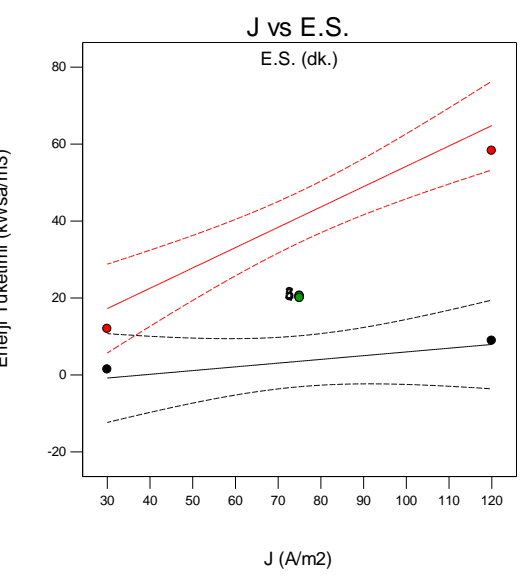

b)

Şekil 5. Enerji Tüketimi a) EK Prosesi, b) EOx Prosesi E.S. : Elektroliz Süresi, J: Akım Yoğunluğu (A/m²) 
EK prosesi sonrası elde edilen KOİ giderim verimleri \% 60-65 düzeyinde iken, uygulanan aynı akım yoğunlukları ve elektroliz sürelerinde EK prosesi sonrası uygulanan EO prosesi toplam KOİ giderim verimini \% 5-10 oranında artırmıştır. Ayrıca, EK prosesindeki enerji tüketimi EK prosesine göre yaklaşı \% 60 daha yüksektir. Hibrit bir proses olarak EK/EO prosesi denim ürün üretim atıksularının arıtımında kullanımının uygun olduğu belirlenirken, atıksuyun tam anlamıyla geri kazanımı ile işletmede kullanımı açısından kısıtlı kalmıștır. Bu anlamda hibrit proses olarak EK prosesinin yanında daha kuvvetli oksitleyici özelliği olan elektrotların kullanıldığı EO prosesi uygulanmasının daha uygun olacağı düşünülmektedir.

İstatistiksel analiz sonucunda elde edilen $\mathrm{R}^{2}$ ve $\mathrm{R}^{2}$ adj değerlerinin 1'e yakın olması, deney sonuçlarının ve istatistiksel çıkarımların uyumlu olduğunu ve işlem parametrelerinin etkilerinin belirlenmesinde BoxBehnken istatistiksel tasarımının önemli olduğunu göstermiştir.

\section{Kaynakça}

[1] Parekh, B. K. 1979. The role of hydrolyzed metal ions in charge reversal and flocculation phenomena, PhD Dissertation, Pennsylvania State University, State College, PA.

[2] Joffe, L., Knieper, L. 2000. Electrocoagulation Technology Quickly Removes Barium, Total Suspended Solids from a Water-Retention Pond for Fractions of a Cent per Gallon, Industrial Wastewater, 5, 1-5.

[3] Mollah, M. Y. A., Schennach, R., Parga, J. R., Cocke D.L. 2001. Electrocoagulation (EC) Science and Applications. Journal of Hazardous Materials, 84(1), 29-41.

[4] Chen, X., Chen, G. C., Yue, P. L. 2000. Separation of Pollutants from Restaurant Wastewater by Electrocoagulation. Seperation and Purification Technology, 19(1-2), 65-76.

[5] Chiang, L. C., Chang, J. E., We, T. C. 1995. Indirect Oxidation Effect in Electrochemical Oxidation Treatment of Landfill Leachate, Water Res. 29(2) 671-678.

[6] Can, O. T., Gengeç, E., Kobya, M., 2019. TOC and COD Removal from Instant Coffee and Coffee Products Production Wastewater by Chemical Coagulation Assisted Electrooxidation, Journal of Water Process Engineering, 28, 28-35.

[7] Rajkumar, D, Palanivelu, K. 2007. Electrochemical Treatment of Industrial Wastewater. J Hazard Materials, 113, 123-129.

[8] García-García, A., Martínez-Miranda, V., Martínez-Cienfuegos, I. G., Almazán-Sánchez, P.
T., Castañeda-Juárez, M., Linares-Hernández, I. 2015. Industrial Wastewater Treatment by Electrocoagulation-Electrooxidation Processes Powered by Solar Cells, Fuel, 149, 46-54.

[9] Verma, A. K. 2017. Treatment of Textile Wastewaters by Electrocoagulation Employing Fe-Al Composite Electrode, Journal of Water Process Engineering, 20, 168-172.

[10] Khorram, A. G., Fallah, N. 2018. Treatment of Textile Dyeing Factory Wastewater by Electrocoagulation with Low Sludge Settling Time: Optimization of Operating Parameters by RSM, Journal of Environmental Chemical Engineering, 6, 635-642.

[11] Kumar, A., Nidheesh, P. V., Kumar, M. S. 2018. Composite Wastewater Treatment by Aerated Electrocoagulation and Modified PeroxiCoagulation Processes, Chemosphere, 205, 587593.

[12] Khemila, B., Merzouka, B., Chouder, A., Zidelkhir, R., Leclerc, J. P., Lapicqu, F. 2018. Removal of a Textile Dye Using Photovoltaic Electrocoagulation, Sustainable Chemistry and Pharmacy, 7, 27-35.

[13] Bilińska, L., Blusa, K., Gmurek, M., Ledakowicz, S. 2019. Coupling of Electrocoagulation and Ozone Treatment for Textile Wastewater Reuse, Chemical Engineering Journal, 358, 992-1001.

[14] Tavangara, T., Jalali, K., Shahmirzadi, M. A. A., Karimi, M. 2019. Toward Real Textile Wastewater Treatment: Membrane Fouling Control and Effective Fractionation of Dyes/Inorganic Salts Using a Hybrid Electrocoagulation - Nanofiltration Process, Separation and Purification Technology, 216, 550-560.

[15] GilPavas, E., Dobrosz-Gómez, I., Miguel-Ángel, Gómez-García, 2019. Optimization and Toxicity Assessment of a Combined Electrocoagulation, $\mathrm{H}_{2} \mathrm{O}_{2} / \mathrm{Fe}^{2+} / \mathrm{UV}$ and Activated Carbon Adsorption for Textile Wastewater Treatment, Science of the Total Environment, 651, 551-560.

[16] APHA. 2005. American Public Health Association (APHA), Standard Methods for the Examination of Waste and Wastewater (19th ed.), Washington.

[17] Merzouk, K., Madani, A., 2010, Using Electrocoagulation-Electroflotation Technology to Treat Synthetic Solution and Textile Wastewater, Two Case Studies, Desalination, 250, 573-577.

[18] Nawarkar, C. J., Salkar, V. D. 2019. Solar Powered Electrocoagulation System for Municipal Wastewater Treatment, Fuel, 237, 222-226. 